\title{
Efeito do nível de caroço integral de algodão sobre o consumo e digestibilidade aparente da fração fibrosa do feno de braquíaria (Brachiaria decumbens) em ovinos
}

[Effect of increasing level of whole cottonseed on intake and apparent digestibility of fiber fraction of Brachiaria decumbens hay in sheep]

\author{
D.A.B. Teixeira ${ }^{1}$, I. Borges $^{2 *}$ \\ ${ }^{1}$ Zootecnista - Autônomo \\ ${ }^{2}$ Escola de Veterinária - UFMG \\ Caixa Postal 567 \\ 30123-970 - Belo Horizonte, MG
}

\begin{abstract}
RESUMO
Avaliou-se o efeito da inclusão de níveis crescentes $(0,12,24,35$ e 49\%) de caroço de algodão ao feno de braquiária (Brachiaria decumbens) sobre o consumo e digestibilidade da fibra em detergente neutro (FDN), fibra em detergente ácido (FDA), hemicelulose e celulose em ovinos. Foram usados 25 carneiros sem raça definida, adultos, castrados e alojados em gaiolas metabólicas e distribuídos inteiramente ao acaso entre os tratamentos. Não houve diferença entre os tratamentos quanto ao consumo e coeficiente de digestibilidade da FDN. O coeficiente de digestibilidade da FDA foi similar entre os tratamentos exceto no tratamento com inclusão de $49 \%$ de caroço de algodão. O coeficiente de digestibilidade da celulose comportou-se de forma semelhante ao da FDA. O coeficiente de digestibilidade da hemicelulose dos tratamentos com caroço de algodão foi maior do que o do tratamento sem caroço de algodão.
\end{abstract}

Palavras-chave: ovino, braquiária, caroço de algodão, digestibilidade

\begin{abstract}
The effect of increasing level of whole cottonseed (0, 12, 24, 35 and 49\%) to a basic diet of Brachiaria decumbens hay on digestibility coefficient of neutral detergent fiber (NDF), acid detergent fiber (ADF), hemicellulose and cellulose was evaluate in sheep. Twenty five castrated male sheep were randomly allotted to the treatments. No differences between treatments for consumption and digestibility of NDF were observed. The pattern of the digestibility coefficient of ADF was similar for all treatments, except for treatment with $49 \%$ of whole cottonseed. The pattern of the digestibility coefficient of cellulose was similar to the corresponding digestibility coefficient of ADF. The digestibility coefficient of hemicellulose for treatments with whole cottonseed was larger than that with no cottonseed.
\end{abstract}

Keywords: sheep, Brachiaria decumbens, digestibility, whole cottonseed

\section{INTRODUÇÃO}

Vários alimentos destinados aos animais competem na cadeia da alimentação humana, como o milho e a soja, sendo conveniente a utilização de alimentos alternativos, principalmente para ruminantes, os quais são temas de pesquisas que evidenciam seus potenciais nutritivos como substitutos eficazes dos alimentos tradicionais.

Existe uma gama de subprodutos da agroindústria, entre os quais destacam-se as sementes de espécies oleaginosas. Elas são as

Recebido para publicação em 17 de maio de 2004

Recebido para publicação, após modificações, em 8 de setembro de 2004

*Autor para correspondência (corresponding author)

E-mail: iran@vet.ufmg.br 
fontes de lipídios mais usadas na dieta animal por proporcionarem alta densidade energética em substituição aos carboidratos rapidamente fermentáveis, viabilizando a fermentação ruminal e a digestão da fibra.

Abel-Caines et al. (1997) sugeriram que o caroço de algodão é uma excelente fonte de fibra efetiva capaz de auxiliar na ruminação. Clark e Armentano (1993) determinaram a efetividade da fibra detergente neutro do caroço de algodão e grãos secos de destilaria em dietas de vacas de leite em lactação. O caroço de algodão promoveu maior atividade de mastigação do que tais grãos. Esses autores concluíram que o caroço de algodão pode servir como suplemento de fibra efetiva para dietas baseadas em silagem pré-seca de alfafa com baixa relação volumoso:concentrado.

O caroço de algodão como subproduto da agroindústria, resultado do descaroçamento do algodão, tem sido usado como alimento para ruminantes por vários anos, apresentando alto valor nutritivo, aporte de fibra efetiva e boa qualidade de proteína e energia.

O objetivo deste trabalho foi avaliar o efeito da inclusão de níveis crescentes de caroço integral de algodão à dieta sobre o consumo e digestibilidade aparente da fibra em detergente neutro, fibra em detergente ácido, celulose e hemicelulose em ovinos com dieta de caroço de algodão e feno de Brachiaria decumbens.

\section{MATERIAL E MÉTODOS}

O ensaio de digestibilidade aparente foi conduzido em janeiro de 2000, com duração de 28 dias, compreendendo os períodos de adaptação (21 dias) e de colheita de amostras (sete dias).

Foram utilizados 25 carneiros adultos sem raça definida (SRD), pesados antes (média de $38 \mathrm{~kg}$ ) e depois do período experimental. Os animais foram alojados em gaiolas metabólicas individuais, apropriadas para coleta de urina e fezes, simultaneamente. As gaiolas dispunham de bebedouro e cocho em aço inoxidável e cocho de polietileno para sal mineral.
Os tratamentos foram cinco dietas experimentais com níveis crescentes de inclusão do caroço de algodão integral de $0,12,24,35,49 \%$ e feno de Brachiaria decumbens. A composição química das dietas experimentais, em percentagem da matéria seca (MS) encontram-se na Tab. 1.

Tabela 1. Composição química das dietas (\% de matéria seca) para ovinos de acordo com o nível de inclusão do caroço de algodão

\begin{tabular}{lccccccc}
\hline & $0 \%$ & $12 \%$ & $24 \%$ & $35 \%$ & $49 \%$ & Feno & $\begin{array}{c}\text { Caroço de } \\
\text { algodão }\end{array}$ \\
\hline PB & 3,48 & 5,23 & 6,99 & 8,74 & 10,50 & 3,99 & 23,19 \\
EE & 1,25 & 3,19 & 5,13 & 7,06 & 9,00 & 1,43 & 22,76 \\
FDN & 62,15 & 59,75 & 57,35 & 54,94 & 52,54 & 71,26 & 43,17 \\
FDA & 46,78 & 44,45 & 42,13 & 39,80 & 37,47 & 52,45 & 25,93 \\
HCEL & 15,37 & 15,30 & 15,22 & 15,15 & 15,07 & 18,81 & 16,13 \\
CEL & 41,59 & 41,65 & 47,67 & 43,80 & 43,80 & 48,68 & 18,0 \\
EB(kcal/kg) & 4031 & 4157 & 4283 & 4409 & 4536 & 4620 & 5840 \\
\hline PB= proteína bruta; EE= extrato etéreo; FDN= fibra & FE \\
detergente neutro; FDA= fibra detergente ácido; HCEL= \\
hemicelulose; CEL= celulose; EB= energia bruta.
\end{tabular}

A ingestão de MS foi à vontade, com livre acesso à água e à mistura mineral. A dieta foi dividida em duas refeições iguais, oferecidas às 8 e 18 horas. O total de alimento oferecido foi a soma do consumido no dia anterior acrescido de $20 \%$, para que se obtivesse a estabilização do consumo.

A colheita de urina e de fezes foi feita seguindo as recomendações (rotina) para experimentos dessa natureza. A colheita de urina ocorreu pela manhã, mensurando-se o volume obtido e retirando-se aliquotas de $10 \%$. A de fezes foi feita pesando-se o conteúdo total e retirando-se $20 \%$ da quantidade diária defecada.

O processamento do material colhido seguiu os procedimentos recomendados para experimentos de digestibilidade. Fez-se a pré-secagem em estufa de ventilação forçada a $60 \pm 5^{\circ} \mathrm{C}$. As análises de fibra em detergente neutro, fibra em detergente ácido, hemicelulose e celulose seguiram o método seqüencial descrito por Van Soest (1991).

O delineamento experimental foi o inteiramente ao acaso, com cinco tratamentos e cinco repetições por tratamento. Os dados obtidos foram submetidos à análise de variância utilizando-se o sistema de análises estatísticas e genéticas (Sistema..., 1995) e as médias 
comparadas pelo teste Student Newman Keuls, no nível de $5 \%$ de probabilidade.

\section{RESULTADOS E DISCUSSÃO}

A ingestão de MS foi superior à indicada pelo National Research Council (Nutrient..., 1985) de $53,19 \mathrm{~g}$ de $\mathrm{MS} / \mathrm{kg}^{0,75}$, para ovinos adultos em mantença, com exceção do tratamento com feno. O consumo foi próximo dos $60,97 \mathrm{~g} / \mathrm{kg}^{0,75}$ obtidos por Rodriguez (1984), que trabalhou com níveis distintos de substituição de feno de braquiária por farelo de arroz $(0,25,50,75 \%)$. Van Soest (1994) afirmou que forragens com altos níveis de fibra $(71,3 \%$ de fibra em detergente neutro e $52,4 \%$ de fibra em detergente ácido) permanecem por mais tempo no trato gastrintestinal gerando menor consumo voluntário. Rogério (2001), ao trabalhar com ovinos, verificou que o consumo de MS foi de $72,30 \mathrm{~g} / \mathrm{kg}^{0,75}$ quando se acrescentou $24 \%$ de caroço de algodão ao feno de tifton. Brosh et al. (1989), ao fornecerem $0,6,12,18$ e $24 \%$ na MS da dieta de caroço de algodão para bovinos de corte, verificaram maior consumo de MS até $12 \%$ de caroço de algodão na matéria seca das dietas.

Não houve diferença $(\mathrm{P}>0,05)$ entre os cinco tratamentos quanto ao consumo diário de fibra em detergente neutro (Tab. 2) e fibra em detergente ácido e quanto ao coeficiente de digestibilidade da fibra em detergente neutro.

Tabela 2. Consumo médio diário $\left(\mathrm{g} / \mathrm{kg}^{0,75}\right)$ e coeficiente de digestibilidade da fibra em detergente neutro (DFDN) e fibra em detergente ácido (DFDA), de acordo com o nível da inclusão do caroço de algodão

\begin{tabular}{|c|c|c|c|c|}
\hline & $0 \%$ & $12 \%$ & $24 \%$ & $\mathrm{CV}(\%)$ \\
\hline Consumo FDN & $39,92 \mathrm{a}$ & $48,93 a$ & $47,80 \mathrm{a} 46,00 \mathrm{a} 41,42 \mathrm{a}$ & 13,24 \\
\hline DFDN & $41,55 \mathrm{a}$ & $46,07 \mathrm{a}$ & $45,21 \mathrm{a} 43,26 \mathrm{a} 36,75 \mathrm{a}$ & 14,79 \\
\hline Consumo FDA & $28,66 \mathrm{a}$ & $34,59 a$ & 33,13 a $31,34 a$ 27,98a & 13,35 \\
\hline DFDA & $40,89 \mathrm{a}$ & $42,04 a$ & $36,15 \mathrm{a} 35,54 \mathrm{a} 21,71 \mathrm{~b}$ & 21,37 \\
\hline
\end{tabular}

Segundo Villela et al. (1996), para vacas leiteiras, o consumo de fibra em detergente neutro não foi influenciado pela inclusão do caroço de algodão. Karalazos et al. (1992) observaram que os coeficientes de digestibilidade da fibra em detergente neutro e fibra em detergente ácido foram maiores com a adição de $35,5 \%$ de caroço de algodão e declinaram quando a substituição foi de $53 \%$ de caroço de algodão ( $12 \%$ de óleo). Keele et al. (1989) verificaram que o coeficiente de digestibilidade da fibra em detergente ácido não foi reduzido pela inclusão de $25,3 \%$ de caroço de algodão (5,8\% de óleo) na dieta de vacas leiteiras não lactantes.

Zinn (1989) relatou que o aumento do óleo como suplemento de 0 a $8 \%$ na dieta de novilhas provocou diminuição linear da digestão da fibra em detergente ácido. Quanto ao coeficiente de digestibilidade da fibra em detergente ácido, não houve diferença entre os tratamentos até a inclusão de $35 \%$ de caroço de algodão, mas o tratamento com $49 \%$ de inclusão diferiu dos demais; este apresentou $8,3 \%$ de extrato etéreo. Isto provavelmente é atribuído ao efeito inibidor do óleo sobre a digestibilidade da fibra, manifestando-se de maneira mais acentuada na fibra em detergente ácido, sugerindo que a depressão na digestibilidade é maior na celulose que na hemicelulose.

Segundo Devendra e Lewis (1974), a redução na digestibilidade da FDA foi maior quando os níveis de fibra na ração foram mais baixos ou nas dietas com ácidos graxos insaturados. Os resultados do tratamento com $49 \%$ de caroço de algodão confirmam os achados desses autores. Para a fibra em detergente neutro, contudo, podese fazer apenas ligeira inferência pois $o$ coeficiente de digestibilidade da FDN não se alterou com a inclusão crescente do caroço de algodão.

Rogério (2001) verificou decréscimo no consumo de todas as frações fibrosas analisadas quando houve elevação dos níveis de caroço de algodão na dieta de ovinos. Os coeficientes de digestibilidade da fibra em detergente neutro e fibra em detergente ácido foram inferiores no tratamento com feno de tifton e com a inclusão de $45 \%$ de caroço de algodão.

O consumo médio diário e o coeficiente de digestibilidade da hemicelulose não foram diferentes entre os tratamentos que continham caroço de algodão, no entanto, diferiram do tratamento-controle, composto de feno de braquiária, o qual mostrou-se inferior aos demais (Tab. 3). 
Tabela 3. Consumo médio diário $\left(\mathrm{g} / \mathrm{kg}^{0,75}\right)$ e coeficiente de digestibilidade da hemicelulose (DHCEL) e da celulose (DCEL), de acordo com o nível de inclusão do caroço de algodão

\begin{tabular}{lcccccc}
\hline & $0 \%$ & $12 \%$ & $24 \%$ & $35 \%$ & $49 \%$ & CV (\%) \\
\hline Consumo de hemicelulose & $9,65 \mathrm{~b}$ & $12,18 \mathrm{a}$ & $12,45 \mathrm{a}$ & $12,63 \mathrm{a}$ & $11,84 \mathrm{a}$ & 12,92 \\
DHCEL & $56,26 \mathrm{~b}$ & $68,90 \mathrm{a}$ & $73,62 \mathrm{a}$ & $78,35 \mathrm{a}$ & $73,83 \mathrm{a}$ & 10,56 \\
Consumo de celulose & $25,91 \mathrm{ab}$ & $30,85 \mathrm{a}$ & $29,23 \mathrm{ab}$ & $27,11 \mathrm{ab}$ & $23,73 \mathrm{~b}$ & 13,14 \\
DCEL & $48,55 \mathrm{a}$ & $52,39 \mathrm{a}$ & $48,77 \mathrm{a}$ & $45,76 \mathrm{a}$ & $33,36 \mathrm{~b}$ & 14,67 \\
\hline
\end{tabular}

Médias seguidas por letras distintas diferem entre si $(\mathrm{P}<0,05)$ pelo teste SNK.

$\mathrm{CV}=$ coeficiente de variação.

O consumo e a digestibilidade da hemicelulose apresentaram o mesmo tipo de resposta, isto é, não houve redução na digestão da hemicelulose em função da inclusão crescente de extrato etéreo nas dietas. Os coeficientes de digestibilidade da celulose foram semelhantes entre os tratamentos, exceto entre os tratamentos com $12 \%$ e $49 \%$ de inclusão do caroço de algodão. Neste último a digestibilidade da celulose foi mais baixa. Rogério (2001) observou redução no coeficiente de digestibilidade da celulose com a adição de 35 e $45 \%$ de caroço de algodão.

Quanto ao consumo de celulose, ele foi maior apenas no tratamento com $12 \%$ de caroço de algodão em relação ao tratamento com $49 \%$. Os outros tratamentos colocaram-se em posição intermediária. McAllan et al. (1983) observaram que a digestibilidade da celulose e da xilose foram afetadas mais extensivamente do que a da manose, da galactose e da arabinose, fato atribuído aos efeitos negativos da suplementação de óleo sobre o crescimento de protozoários e bactérias celulolíticas.

A digestibilidade da hemicelulose foi menor apenas na dieta controle. Possivelmente a hemicelulose do caroço de algodão deve ser mais digestível do que a hemicelulose do feno. A menor digestibilidade da celulose na dieta com $49 \%$ de caroço de algodão pode ser explicada pela incrustação da lignina formando complexos ligno-polissacarídeos, a qual formaria uma barreira física que impediria a ação das bactérias celulolíticas.

Hatfield (1991) citou que a celulose possui graus de cristalinidade na sua estrutura, os quais afetam a taxa de degradação pelos microrganismos do rúmen, limitando o acesso da enzima fibrolítica à parede celular. Dehority (1991) estudou a interação entre a ecologia microbiana e a fermentação da parede celular, discorrendo sobre as evidências de interação dos componentes da planta e suas características estruturais, tais como localização de polissacarídeo, ligações covalentes, pontes de hidrogênio e espaço de acesso para atuação da enzima microbiana. Assim, o autor indicou a possível existência de componentes importantes da parede celular ou interações diretas ou mediadas por ligações que pudessem favorecer ou dificultar a degradação da celulose.

\section{CONCLUSÕES}

Os níveis de inclusão do caroço de algodão propostos não alteraram os consumos de FDN e FDA e a digestibilidade da FDN mas não foram benéficos quanto à digestibilidade da FDA na dieta com $49 \%$ de inclusão do caroço de algodão. $\mathrm{O}$ consumo e a digestibilidade da hemicelulose melhorou com todos os níveis de inclusão do caroço de algodão, contudo, a inclusão de $49 \%$ do caroço de algodão à dieta não foi benéfico para o consumo e a digestibilidade da celulose.

\section{REFERÊNCIAS BIBLIOGRÁFICAS}

ABEL-CAINES, S.F.; GRANT, R.J.; HADDAD, S.G. Whole cottonseeds or a combination of soybeans and soybean hulls in the diets of lactating dairy cows. J. Dairy Sci., v.80, p.13531357, 1997.

BROSH, A.; HOLZER, Z.; LEVY, D. Cottonseed for protein and energy supplementation of high - roughage diets for beef cattle. Anim. Prod., v.48, p.513-518, 1989.

CLARK, P.W.; ARMENTANO, L.E. Effectiveness of neutral detergent fiber in whole cottonseed and dried distillers grains compared with alfafa haylage. J. Dairy. Sci., v.76, p.26442650, 1993. 
DEHORITY, B.A. Microbial ecology of cell wall fermentation. In: JUNG, H.G.; BUXTON, D. R.; RALPH, J.; HATFIELD, R.D. International symposium on forage cell wall structure and digestibility. Madison: American Society of Agronomy, 1991. Cap.17, p.425-453.

DEVENDRA, C.; LEWIS, D. The interaction between dietary lipids and fibre in sheep. Malay. Agric. Res., v.3, p.228-241, 1974.

HATFIELD, R.D. Cell wall polysaccharide interactions and degradability. In: JUNG, H.G.; BUXTON, D.R.; RALPH, J. International symposium on forage cell wall structure and digestibility. Madison: American Society of Agronomy, 1991. Cap. 12, p. 285-313.

KARALAZOS, A.; DOTAS, D.; BIKOS, J. A note on the apparent digestibility and nutritive value of whole cottonseed given to sheep. Anim. Prod., v.55, p.285-287, 1992.

KEELE, J.W.; ROFFER, R.E.; BEYERS, K.Z. Ruminal metabolism in nonlactating cows fed whole cottonseed or extruded soybeans. J. Anim. Sci., v.67, p.1612-1622, 1989.

McALLAN, A.B.; KNIGHT, R.; SUTTON, I.D. The effect of free and protected oils on the digestion of dietary carbohydrates betwen the mouth and duodenum of sheep. Br. J. Nutr., v.49, p.433, 1983.
NUTRIENT requeriments of sheep subcommittee on sheep nutrition. Washington: Academic, 1985. 99p.

RODRIGUEZ, N.M. Valor nutritivo do farelo de arroz para ruminantes. 1984. 127f. Tese (Professor Titular) - Escola de Veterinária, Universidade Federal de Minas Gerais, Belo Horizonte.

ROGÉRIO, M.P. Belo Horizonte: Consumo, digestibilidade aparente e balanço de nitrogênio de dietas contendo feno de "tifton 85" (Cynodon spp) e níveis de caroço de algodão em ovinos. 2001. (Mestrado) - Escola de Veterinária, Universidade Federal de Minas Gerais, Belo Horizonte.

SISTEMA de análises estatísticas e genéticas SAEG. Viçosa: UFV, 1995.

VAN SOEST, P.J. Nutritional ecology of the ruminant. New York: Cornell University, 1994. $476 \mathrm{p}$.

VILLELA, S.D.J.; FILHO, S.C.V.; SILVA, J.F.C. et al. Caroço de algodão para vacas leiteiras I. Consumo de nutrientes, produção e composição do leite. Rev. Bras. Zootec., v.25, p.298-308, 1996.

ZINN, R.A. Influence of level and source of dietary fat on its comparative feeding value in finishing diets for feedlot steers: metabolism. $J$. Anim. Sci., v.67, p.1038-1049, 1989. 